\title{
Democracy as the Communitarian Ideal
}

\author{
Donald Poochigian \\ Department of Philosophy and Religion, University of North Dakota, Grand Forks, North Dakota, USA \\ Email: donald.poochigian@und.edu
}

Received July 22 ${ }^{\text {nd }}, 2013$; revised August 22 ${ }^{\text {nd }}, 2013$; accepted August 30 ${ }^{\text {th }}, 2013$

\begin{abstract}
Copyright (C) 2014 Donald Poochigian. This is an open access article distributed under the Creative Commons Attribution License, which permits unrestricted use, distribution, and reproduction in any medium, provided the original work is properly cited. In accordance of the Creative Commons Attribution License all Copyrights @ 2014 are reserved for SCIRP and the owner of the intellectual property Donald Poochigian. All Copyright (c) 2014 are guarded by law and by SCIRP as a guardian.
\end{abstract}

\begin{abstract}
Democracy is distinguished by optimal integration of diverse public values, identifying the most encompassing set of mutually accepted elements defining the contemporary circumstance. Individual orderings are integrated into a continuum by rearranging common elements into conformity with every other ordering. Sequencing common elements differently, translation from individual to individual occurs by reordering elements in an understanding according to sequencing of another understanding. Utilizing the reordering process, apparent contradiction between concepts is eliminated, each smoothly transitioning into its opposite, fusing all into a transmutative whole. By this function, an axiom system can be generated from its constituent axioms in any order.
\end{abstract}

Keywords: Democracy; Solipsism; Communitarianism

\section{Introduction}

\section{Modernism and Postmodernism}

Acknowledging the conflicting character of egoism and altruism manifest in democratic theory within the liberal tradition, Josiah Royce observes, "We are by nature proud, untamed, restless, insatiable in our private self-will. We are also imitative, plastic, and in bitter need of ties” (Royce, 1908: p. 125). Encapsulated is the liberal democratic challenge of integrating the competing dispositions of egoism and altruism. Confounding integration is the liberal priority of egoism, expressed as "freedom".

This priority is attributable to an implicit presumption of solipsism, presenting the liberal democratic conundrum of communally integrating essentially isolated subjective worlds. On enlightenment positivist assumptions, this conundrum does not appear. Assumed is a universal human reason identifying an objective rational reality.

Ushering in the Twentieth Century, however, a darker vision accommodating the irrational appears. On post World War I logical positivist assumptions, there is a universal human reason identifying an objective rational reality, and an individual human emotion identifying a subjective irrational reality. Universal reason is to constrain individual emotion. On post World War II modernist and postmodernist assumptions, there is an individual human emotion identifying a subjective reality.

"Modernists" are rule believers considering similarity a constant. A nominal reality constituting a universal rationality is assumed, inconsistency being a qualification. "Post-modernists" are rule skeptics considering similarity an inconstant. A nominal reality constituting a personal irrationality is assumed, inconsistency being a contradiction.

"Modernists" and "Post-Modernists" alike, however, primar- ily concern preserving individual identity, and sacrificing communal identity. Helpful, perhaps, in distinguishing these groups is a gross categorization. Majoritarians and contractarians are understandable as "Modernists". Libertarians are understandable as "Post-Modernists".

\section{Individualism}

Libertarianism sacrifices all communal identity for individual identity. Majoritarianism and utilitarianism sacrifice some communal and some individual identities. None sustain both communal and individual identities. Not assuming universal a priori human values, all are logically consistent with undemocratic forms. Because democracy is communal, modern democratic theories are unstable.

A value is an end pursued. An ethic is a universal value. A subjective ethic is an unshared universal value. All ethics being subjective, all subjects pursue different ends. Pursuing an end different from another's end is to have a self-interested value. Therefore, all values are self-interested.

Being so,

Any undertaking that involves more than one man, requires the voluntary consent of every participant. Every one of them has the right to make his own decision, but none has the right to force his decision on the others. (Rand, 1964: p. 93).

Voluntary cooperation is requisite because,

Individual rights are not subject to a public vote; a majority has no right to vote away the rights of a minority; the political function of rights is precisely to protect minorities from oppression by majorities (and the smallest minority on earth is the individual) (Rand, 1964: p. 99). 
Concerning the limits of self-interested values, though, "The lines are sometimes hard to draw" (Sen, 1995: p. 148). Thus, "it may seem impossible for the parties to ascertain these persons' good and therefore to make a rational agreement” (Rawls, 1996: p. 307).

Philosophically, the democratic challenge is to formulate a logically stable reconciliation of individual and communal values. Michael Sandel well summarizes this challenge. Because "Justice is inescapably judgmental" (Sandel, 2009: p. 261) without "guarantee" of "agreement" on "hard moral questions," (Sandel, 2009, p. 268) judgment is subjective. Assuming concomitant duties to figure "out what we believe and why" (Sandel, 2009: p. 23) and "a strong sense of community," (Sandel, 2009: p. 263) no objective standard of reconciliation for these competing responsibilities is provided. Indeed, "I don't have a fully worked out answer to this question” (Sandel, 2009: p. 261).

\section{Communalism}

Resolution is conceptual, distinguished by optimal integration of diverse public values. Assuming solipsism, the most encompassing set of mutually accepted elements defining the contemporary environment is identified. These elements being ordered differently by different individuals, orderings are integrated into a continuum by rearranging common elements in one ordering to conform with another ordering.

Only by understanding it an infinitely divisible transmutative continuum can a continuously representative democracy be composed. Individuals sequencing common elements differently, translation from one to another occurs by reordering elements in an understanding according to sequencing of another understanding. Utilizing the reordering process, any apparent contradiction between concepts is eliminated, each smoothly transitioning into its opposite, fusing all into the logical equivalence of a bijective whole.

By this function, a whole can be generated from its constituents in any order. Constituting a continuum, each constituent becomes the other. Integrated into a single entity, they are consistent, aspects of a common whole. Conflict is the product of the failure to conflate the superficially distinct values of different people.

\section{Democratic Theory}

Defining democracy is a community of individuals. Presented is the logical conundrum of the individual many as the communal one, and the communal one as the individual many. How can parts constitute a whole, and a whole constitute parts, $a+b$ $=c$ and $c=a+b$ ? Introduced is a variation of, "Frege's Puzzle: how, if true, can " $\mathrm{A}=\mathrm{B}$ " differ in cognitive significance from “A=A”? (Bealer, 2008).

Adhering to the law of the excluded middle, traditional democratic theories resolve the conundrum by sacrificing either individualism or communalism. Doing so converts democracy into something other than itself, however. To be sought is a democratic theory sacrificing neither individualism nor communalism.

Challenging the possibility of a coherent democracy are the competing ethical claims of egoism and altruism. Hereby the good of one individual determines the individual good of other individuals which determines the good of the one individual.
John Locke acknowledges this circularity when asserting, "For his labor being the unquestionable property of the laborer, no man but he can have a right to what that is once joined to, at least where there is enough and as good left in common for others" (Locke, 1952: p. 17, italics added).

Considerate of linearity, primacy of private and public property is indeterminate. Liberal ethics being wedded to linearity, this indeterminacy forms its basis. Primacy of the private is egoism, and primacy of the public is altruism. Both, however, are self-contradictory, rendering liberal ethics incomplete.

Argument by egoism. Assuming altruism an absolute duty, each is obliged to sacrifice everything that individual has to another individual, who must sacrifice everything that individual has to another, and so forth Now none will have anything, all perishing. All perishing, none can fulfill the absolute duty to sacrifice everything to another. Therefore, altruism as an absolute duty is self-contradictory.

Argument by altruism. Alternatively, assuming “'human material wants' ... are, for practical purposes, insatiable, or unlimited" (McConnell, 1960: p. 21), then all "are in the condition which is called war... and the life of man, solitary, poor, nasty, brutish, and short” (Hobbes, 1969: p. 143). All perishing, none can fulfill "The purpose of morality [which] is to teach you, not to suffer and die, but to enjoy yourself and live" (Rand, 1992, Chapter VII, circa p. 25). Therefore, egoism as an absolute duty is self-contradictory.

Democratic theories seek integration of egoism and altruism. Integration is presented as complete or incomplete. Casuistry presents it as a complete universal continuum. Failing this, utility and majority present it as an incomplete partial discontinuum. Failing this, community presents it as a complete axiomatic continuum.

Argument by casuistry. Casuistry assumes infinity a limitless continuum. Every element within this continuum constitutes a unique nexus of relations to all other elements at a singularity. All other elements composing an infinity, determined is a single limitless description of the element.

Although this infinite description is traceable in different ways, all tracings converge on a single description. Convergence is meeting at a limit, however. Infinity is limitless. Therefore, there is no convergence at infinity.

Because an infinite description is traceable in different ways, at any sequence limit, an infinity of extensions are equally justified. Convergence being one description within infinity, divergence is more probable. Diverging, engendered is "a war of all against all” (Hobbes, De Cive, 1651, Chapter One, "Of the state of men without Civill Society", "In the mere state of Nature", XIII).

Classical liberal democratic theory resolves "a war of all against all” by assuming universally shared intuitive identity of limited discontinua mapped to the limitless continuum. There being such intuition, there is no war. There is war. Therefore, there is no such intuition.

Although there is war, there is not "a war of all against all". Therefore, there is some such intuition. This intuition is encompassed in anarchic communalism, which is provided in response to chaotic individualism.

Francis Fukuyama presents its content declaring, "the ultimate triumph of Western liberal democracy [is] an unabashed victory of economic and political liberalism” (Fukuyama, 1989, p. 3). However, "economic and political liberalism" have not always rested easily together. Thus, abandonment of indivi- 
dualism presents at least two arguments.

Argument by utility. Suppose individuals equal in all abilities, who all would be better off if exercising different abilities in a division of labor determined by chance. More familiar with different abilities by experience, subsequently all would be better off if each continues in their respective specialties. Each would exhibit a comparative advantage in that individual's specialty for the benefit of all.

Now suppose one specialty requires proportionately more resources than the other specialties to produce optimal benefit for all. Assume as well optimal benefit increases in proportion to the development of expertise and corresponding increase in proportion of resources. Generated is an increasing inequality in the distribution of resources consistent with the greatest benefit of all. If feudal subservience is optimal, it is justified on utilitarian assumptions.

Argument by majority. Majoritarian democracy is unstable. Majority disenfranchisement of the minority being consistent with majoritarian democracy, paradoxically majoritarianism can devolve consistently into a contradictory nonmajoritarianism. This occurs as an ever diminishing majority repetitively disenfranchises an ever diminishing minority to the limit of an aristocracy of two. A majority presupposing a minority, and a minority being now impossible, a majority is now impossible.

Integration is logically possible only by each transmuting into the other. Constituting a continuum, each becomes the other. Integrated into a single entity, they are consistent, aspects of a common whole. Conflict is the product of the failure to conflate the superficially distinct values of different people.

\section{Democratic Ethics}

All democratic theories considered proceed on the assumption, being extended in time and/or space, all qualitative experience is endlessly divisible in no necessary order. Formed like an irrational number is, "an infinite decimal with no set of consecutive digits repeating itself indefinitely" ("irrational number,” Mish, et al., 619). Unable to comprehend such an infinity, organization into a limited number of groups makes qualitative experience rational. Within a group, each member is considered the same. Although no two things are exactly alike, differences are ignored to facilitate functioning in the world.

Because individuals can understand what is in different ways, order in human relations is explainable only assuming people have a common conception of reality to at least some extent. Otherwise concurrence on anything is impossible since individuals cannot arrive at an understanding by agreement, for this requires another understanding, and this still another, and so forth. Human rights are constituent of this shared understanding.

Such understanding establishes trust, the ability to act in security so consideration of behavior is unnecessary. There is nothing strange in this, trust being a necessary condition for survival of any living being. Paranoia is incapacitating, leaving it impossible for an organism to function. Unable to do what is necessary to survive, it must quickly perish. Fundamental to trust is grouping others according to common expectations toward them. Members of a group can be "trusted" to function in a certain manner. Exception can occur, this determining when it is necessary to consider the behavior of a particular individual.

Identified by this means is what might be designated the "dispositional nature" of something in contrast to its "constitu- tional nature". Meant by constitutional nature is the criterion of class membership, and by dispositional nature the character of class members. These are not necessarily the same for all since something can behave in any way and still be a class member. Only after class members are identified is their dispositional nature determinable.

Understanding there to be universal values, these are identifiable by considering the requirements for order in human relations. Basic to any account of the survival of human beings is people have expectations about how they ought to be treated by others, and are resentful if others do not treat them in the expected ways. It is difficult to imagine humans surviving individually and as a species if this is not so. Correspondingly it is difficult to account for human survival if all do not accept a concurrent responsibility to treat others in the ways they expect. Animosities would be such that, "they are in the condition which is called war... and the life of man, solitary, poor, nasty, brutish, and short” (Hobbes, 1969: p. 143).

\section{Democratic Egoism}

Such a focus requires presuming an Aristotelian or Thomistic genetically determined organically integrated self-sufficient universe. A liberal anarchy of self-determining individuals can be supposed in no other way. Within liberal democratic tradition, integration of egoism and altruism is frequently thought provided by rational choice theory, especially by economists. Illustratively,

Different sciences have various explanations for why people do what they do ... Economists ... argue that if we want an analysis that's simple enough to apply to policy problems, ... heavy psychological explanations are likely to get us mixed up. At least to start with, we need an easier underlying psychological foundation. And economists have one-self-interest. People do what they do because it's in their self-interest (Colander, 2006: p. 188).

Often overlooked is the metaphysical implication of "selfinterest”. Solipsism is fundamental to rational choice theory such that,

The world is my world: this is manifest in the fact that the limits of language (of that language which alone I understand) mean the limits of my world (Wittgenstein, 1974, nt. 5.62, p. 57). ... The subject does not belong to the world: rather, it is a limit of the world (Wittgenstein, 1974, nt. 5.632, p. 57). Here it can be seen that solipsism, when its implications are followed out strictly, coincides with pure realism. The self of solipsism shrinks to a point without extension, and there remains the reality co-ordinated with it (Wittgenstein, 1974, nt. 5.64, p. 58).

Insofar as "The world is my world", the individual unavoidably composes the individual's own world. Now every calculation by the individual is rational because controlling for all variables.

Assuming rationality is conformity by injective mapping to a rule, the fundamental liberal presumption of solipsism confronts the difficulty of,

"obeying a rule" is a practice. And to think one is obeying a rule is not to obey a rule. Hence it is not possible to obey a rule "privately": otherwise thinking one was ob- 
eying a rule would be the same thing as obeying it (Wittgenstein, 1968, nt. 202, p. $81^{\mathrm{e}}$ ).

Here "my world" cannot be known to be bound by a rule. Identity being application of a rule, identity within "my world" cannot be known to be accurate. Only within "our world", a public world, is obedience to a rule knowable, since you can verify my usage.

But, because your judgment occurs within "your world”, and "your world" is private, it cannot be known to be accurate. Thus, you cannot know if my identity is accurate. Additionally, because I only can know your judgment in "my world”, I cannot know if my identity of your judgment is accurate. Therefore, obedience to a rule is unknowable. If rationality is conformity to a rule, then it is unknowable.

Even putting this aside, rational choice is less than optimal. Although insofar as rational calculation requires computation of the greatest good in every circumstance, when such computation constitutes an opportunity cost for greater good, rational calculation is inefficient. More efficient is a common means to a common end. Even here, however, inefficiency appears in another's unpredictable actions.

Libertarianism assuming another separated from one's solipsistic world, all variables cannot be controlled, rational choice being optimal only accidentally. Rational choice is optimal essentially only within a determinedly integrated universe. Seemingly, either libertarianism must be accepted and optimality abandoned, or optimality must be accepted and libertarianism abandoned.

\section{Democratic Self}

Challenging liberal egoism is quantum theorist David Bohm's observation, "the entire universe (including, of course, all observers of it), must be regarded as forming a single indivisible unit with every object linked to its surroundings" (Bohm, 1989, 585). So being, anything is identifiable by an infinity of properties determining its location within an endlessly divisible world. A particular is the nexus of all relations of all constituents of the world at a singularity within the world.

As Immanuel Kant observes, however, it is logically impossible to understand an infinity of particulars. This is indicated in Kant's first antinomy. To what this comes is to be coherent is to cohere. For any coherent infinity of particulars, there is an incoherent infinity of particulars not constituent of it. Therefore, an infinity of particulars is incoherent.

To be coherent is to be understandable. To be incoherent is to be not understandable. Therefore, an infinity of particulars is not understandable. Infinity being incoherent and incomprehensible, however, it cannot be known another infinity of particulars is beyond any infinity of particulars. To know this is to comprehend the infinities as a coherent whole, combining them. Supposed by Kant's argument is infinity as a limitless discontinuum. Hereby, between any two elements of a sequence, there always will not be another. Thus, there is always an infinity beyond any infinity.

Kant is correct assuming a limitless discontinuum, but there is no necessity in a limitless discontinuum. Supposed can be infinity as a limitless continuum. Hereby, "The rational fractions are so dense that between any two of them, no matter how close, there always will be another” (Boyer, 1991, 566). Infinity understood in this manner constitutes an uninterrupted field. As such, it numerically has the value one (" 1 "). Now there is no infinity beyond infinity. Being thus, infinity is necessarily coherent and comprehensible.

Rendering an infinitude of particulars comprehensible is a finitude of particulars constituted by "a limit of the world". Beyond this limit is the observer whereby,

the very idea of making an observation implies that what is observed is totally distinct from the person observing it.

The paradox is avoided by taking note of the fact that all real observations are, in their last stages, classically describable (Bohm, 1989: pp. 584-585).

Hereby "the person observing" is identified by disassociation from a limited "world". Alternatively, a person observed is identified as an autonomous "world" constituted by a limit within the encompassing limited "world". Identifying the person observed is the individual's limits whereby,

among the attributes an object must have are not only those which it shares with objects of its kind (Aristotelian essentialism), but those which are partially definitive of the special character of the individual and distinguish it from some objects of the same kind (Marcus, 1971: p. 191).

Generalized ex post facto, the "attributes" persons constituent of an encompassing "world" share as a "kind" determine the self-determined limit of their "world".

Content of this "world" presents a conservation of energy limiting the possible states of constituents of the "world". Understood as component of each constituent of the whole, a complete translation of the shared "attributes" of any one constituent of a "world" can be made to any other constituent of the "world". Distinguishing individual constituents is the potential and kinetic status, as well as sequencing, of the "attributes". Now each constituent is distinguishable as a different state of the constant "attributes".

Assuming humans fundamentally do not agree is as analytic as assuming they fundamentally do agree. Fundamental agreement models anthropological culture. Self-interest can be accommodated by evolutionary biology. Constituent of universal values is a set of tolerated deviant values. Incorporation of this set provides a pool of values for adaptation to environmental alteration. Supposing "People do what they do because it's in their self-interest" focuses on the aberrant, then, not the common (Colander, 2006: p. 188). Focusing on the aberrant, a stable democracy is inexplicable. Only by focusing on the common is a stable democracy explicable.

\section{Democratic Community}

Complicating resolution of these apparently conflicting alternatives is liberalism explicitly, if not implicitly, denies the reality of an organically integrated self-sufficient universe. Substituted for the organicism of an Aristotle or Thomas is mechanism. Distinguishing mechanism from organicism is a mechanic system is a transformative discontinuum, and an organic system is a transmutative continuum.

Constitutive of a transformative discontinuum is a sequence, a relation of identifiable particulars. Relation is a continuum between particulars. How is a particular identifiable within a continuum? An identifiable constituent of a continuum is represented by a commutative ring with unity (Stewart, 1995: p. 78). Fusion of constituents renders a particular distinguishable from 
the continuum. Diffusion of constituents renders a particular indistinguishable from the continuum. Cyclic transitive marginal conversion of constituents from fusion to diffusion and diffusion to fusion renders a particular distinguishable and indistinguishable from the continuum.

In a transmutative continuum, "the universe of [an] object transmutes into a ... parallel [universe] ..., with each universe containing a unique single possible state of that object” (Rouse, 2006). Such a transmutation proceeds considering,

Between two perceived perspectives which are similar, we can imagine a whole series of other perspectives, some at least unperceived, and such that between any two, however similar, there are others still more similar. In this way the space which consists in relations between perspectives can be rendered continuous (Baum, 1964: p. 20). reby,

Being "rendered continuous", constituted is a dense set whe-

An ordered set is said to be dense, if it contains at least two elements and no neighboring elements. A dense set is always infinite, because every finite set containing at least two elements has also neighboring elements (Kamke, 1950: p. 70).

Distinguished is a commutative ring with unity ("ring”). Considering a ring, exhibited is a function whereby constituents reciprocally fuse into the same indistinguishable whole by repetitive iterative application of the "+" conjunctive function in any sequential order, and diffuse into the same distinguishable parts by repetitive iterative application of the "." disjunctive function in any sequential order. Constituents as fused whole are an object, and as diffused parts are not an object. Being "rendered continuous", identity is free from concealed contradictions.

Acknowledging identity as a simple primitive, a "whole series of other perspectives" provides for environmental transmutation by presenting disjunctives of any "two perceived perspectives which are similar". Differentiating these disjunctive "other perspectives" is their exclusive or inclusive resolution. Exclusive resolution identifies a conjunctive whole of distinguishable parts constitutive of an event, such parts determining instances. Inclusive resolution identifies an implicative whole of indistinguishable parts constitutive of a process, such parts determining aspects.

Incorporating these operations, both entropy and growth presume linearity of a line, not circularity of a ring. Distinguishing them is entropy assumes no constituent of a linear set is constituent of another set, constituting the mechanic. Growth assumes every constituent of a linear set is constituent of another set, constituting the organic. Organicism proceeds by repetitive conjunction of sets, it being possible to conjoin any two things. Spontaneous, intangibles are unconstrained by the law of conservation of energy. Conceptual, sets are intangibles. For any constituent of a set, it is possible to imagine another set in which it is constituent. Sharing a common constituent, it is possible to imagine these sets as joined into a common set, and so forth.

Exhibited are the topological concepts of "closeness" and "neighborhood" tracing the path by which "object transmutes" into object. Every member of a set of elements being a member of a set of subsets of that element in relation to every other member of the initial set of elements, identified is a topological "system of neighborhoods at $x$ ”, whereby, "In a certain sense, a neighborhood of a point $x$ is a set of points which lie 'close' to the point” (Baum 1964, p. 20). That interest can be integrated by a common constituent, and in different orders if integrated, is indicated by topological provision. Whether or not a common constituent integrates sets, and if so in what order, is a spontaneous occurrence.

Manifest is conjunction, relation of identifiable particulars. Relation is a continuum between particulars. How is a particular identifiable within a continuum? An identifiable constituent of a continuum is represented by a ring. Fusion of constituents renders a particular distinguishable from the continuum. Diffusion of constituents renders a particular indistinguishable from the continuum. Cyclic transitive marginal conversion of constituents from fusion to diffusion and diffusion to fusion renders a particular distinguishable and indistinguishable from the continuum.

Sameness occurs by linking individual interest nexuses with fuzzy sets, conforming to chaos theory (Klir \& Yuan, 2002: p. 4). Now, different interests can be integrated into a common whole without introducing contradiction. Disjoints between interests always imaginable, inclusive resolution integrates them as a whole. Disjoints between communities always imaginable, exclusive resolution separates them as a whole. Constituted is a coherent community.

\section{Logical Operators}

Incompatibility arises assuming logic is conformity to a generalized rule. Differentiated by at least time and/or space, no two things are alike in any respect unless identical, and being self-defining if identical, identify nothing else. Something else is identifiable only by a particularized listing. As Margaret Thatcher asserted when Prime Minister, "There are individual men and women... There is no such thing as society" (Keay, 1987).

Ms. Thatcher continued “and there are families”, overlooking families are societies. How, then, are families possible within a solipsistic world where, "who is society? There is no such thing!” (Keay, 1987). Even larger societies are possible, lest the Falklands War was merely equivalent to a sizable football riot.

A particularized listing of "individual men and women" can be integrated into the generalized rule of "society" by conceptual extension from particularized element to particularized element. This proceeds by implementation of logical operators. These concern the distributive identity of the states of being composing experienced and/or imaginable objects sequenced from most like one limiting thing to most like another limiting thing.

Such objects are distributable exclusively to one or the other limiting thing, but not both, or inclusively to both limiting things. Distributed exclusively, the limiting things are separated by emptiness, becoming discontinuous things. Distributed inclusively, the limiting things are integrated by fullness, becoming a continuous thing. Thus, logical operators are not "real objects” (Gödel, 1963: p. 137).

Not so, insofar as no two occurrences are exactly the same, differentiated at least by relational properties, whether occurrences are the same or not is a function of their considered aspects. Since different aspects of the same occurrences can be considered, no two occurrences are objectively identifiable as the same. Thus, similarity is not an objective intuition, it is a 
subjective decision.

Complicating matters is the infinite divisibility of experience spatio-temporally and/or conceptually. Divisibility being infinite, when infinity practically cannot be enumerated, a complete axiomatization is practically impossible. Reasoning can be about clearly specified things or ideas only insofar as each reoccurrence of a primitive term constitutive of an axiom system is enumerated in a reaxiomatization of the axiom system.

Understanding logical operators as states of being, rather than "symbols and precise rules of operation upon these symbols", avoids the effective reaxiomatization constitutive of each reidentity of a symbol (Boyer, 1991: p. 579). This is because considering a limited continuum from $a$ to $b$, there is no doubt of the identity of $a$ and $b$ as the same. Although differing in properties, difference constitutes a transformation of the same thing. Alternately, discontinuity constitutes different things, unless nominally identified as the same thing.

By means of a transformation facilitated by logical operators, $a$ and $b$ are rendered identical. And being identical, they are mutually identifying in every respect. Linked by relation to a common property, an otherwise uncommon property of one becomes the common property of the other. Hereby $a$ and $b$ exactly model one another as perspectives on the same thing, even if their otherwise separate properties are infinite.

Illustration appears in a dialogue occurring in an episode of the popular television series Star Trek: Deep Space Nine:

When you return to the Link, what will become of the en-

tity I am talking to right now?

The drop becomes the ocean.

And if you choose to take solid form again?

The ocean becomes a drop.

…

How many of us are there?

One, and many, it depends on how you look at it ("Behind the Lines,” 1997).

Manifest is democracy in its idealized form. Closest modern approximation to the communitarian ideal constitutive of democracy lies in the thought of such as John Dewey (Dewey, 1969-1975: p. 128) and Charles Taylor (Taylor, 2010).

\section{Logical Functions}

Within the modern liberal presupposition of solipsism, democratic communitarianism is possible only by construction of a common understanding within the wholly isolated solipsistic worlds of different individuals. Identifying another as an autonomous consciousness, sought must be an understanding of that consciousness by mapping its presumed manifestation in the activity of the other to that of oneself when exhibiting a corresponding phenomenal experience or experiences. As Adam Smith expresses, "As we have no immediate experience of what other men feel, we can form no idea of the manner in which they are affected, but by conceiving what we ourselves should feel in the like situation” (Smith, 1984, 9).

Whether phenomenally accurate or not, composed is an understanding of another engendering communal harmony. What is objectively, not subjectively, "real", then, is literally of no consequence, if the consequence is the same. Solely the incomprehensible are excluded from communal identity. This is because they cannot be shared insofar as they are incomprehensible, not constituent of "what we ourselves should feel in the like situation".

Subsequent inconsistency is resolved by reformulation generated in the same manner of mapping as formulation. Rather than understandable as an enumeration in a discontinuous process of axiomatization, reformulation is understandable as a clarification in a continuous process of reaxiomatization. Approached thus, initial formulation is considered as qualified, not abandoned, retained as applicable in relevant circumstance. Preserving coherence in this manner, entropy is avoided.

Relevant to the operational implementation of democratic communitarianism is the impossibility of imagining a wholly disordered universe. Only possible is imagining a more or less ordered universe. This is because occurrences necessarily appear in time and/or space. Time and space being infinitely divisible, occurrences are necessarily teleological, extending to a terminus.

Implementing logical operators, solipsistic worlds extend to one another in a sequence of functional operations. These compose injection, surjection, and bijection. Respectively occurring in successive order, transit is from the personal to the communal.

Injection constitutes a transitional space, a substantively and formally unaltered element in different spaces, represented by $a$ $=a$. As so, it is the integration of elements by a common constituent. Rational choice theory incorporates injection by a constant desire integrating otherwise unrelated personal states of being.

Satisfaction of the integrating desire terminates the sequencing of integrating states into a well founded nonrepeating noncirculating line. Such lines multiplying within the solipsistic world of the individual, composed is an entropic state of disassociated sequences. Disorderly as such, constituted by such a state is ennui.

Ambiguous elements of $a$ and $b$ can be arranged from most like one to most like the other, or not. Arranged from most like to most like, formed is a teleological order. Not so arranged, formed is an entropic order. As teleological, elements constitute an implicative set. As entropic, elements constitute a conjunctive collection.

Approached in this manner, entropy is an open system of constituents and sequences. It is open because a collection of teleological systems. Whereas teleological systems are limited, they do not extend onto one another. Not doing so, intervening any two teleological systems is a disassociative exclusive disjunctive space of absolute emptiness.

Surjection constitutes a transmutative space, a substantively altered element in different spaces, represented by $a=b$. Although linking elements with a common constituency by injection, elements without a common constituency are linked by surjection. Implementation is the transfiguration of an element by adding and/or subtracting constituents. Rational choice theory incorporates surjection by an evolving desire integrating otherwise unrelated personal states of being.

Entropic systems are integrated by the operational function of surjection. Constitutive of the limit of a spatio/temporal extension, $a$, is concurrent constituency of an indefinite number of possible continued extensions “ $b, c, \ldots, n$ ”. Indeterminate as such, concurrent constituency presents the disjunctive " $b$ or $c$ or ... $n$ ”.

Resolution of the disjunctive is exclusive (not both $a$ and $b$ ), or inclusive (both $a$ and $b$ ). Exclusive disjunction discontinues extension; inclusive disjunction continues extension. Whether 
exclusive or inclusive, disjunctive resolution is arbitrary, a nominal "ought". Arbitrary, it can be redetermined, extending to what was previously exclusively identified, and/or retreating from what was previously inclusively identified. By this means, any element can transmute into any other element.

Bijection constitutes a transfigurative space, a substantively unaltered and formally altered element in different spaces, represented by $a_{1}=a_{2}$. As so, implemented is the transformation of an element by rearranging constituents. Rational choice theory incorporates bijection by a shared desire integrating otherwise unrelated interpersonal states of being.

Constitutive of common experience are shared elements. Constitutive of uncommon experience is uncommon ordering of shared elements. Ordering of shared elements constituting interest, community interest is the transformational reordering of shared elements from communal member to communal member in a continuum.

Exhibited is continuous part reordering in transforming extension of continuous whole. Manifest is culture. Democracy is functional only within such a culturally homogenous group. A culturally heterogeneous group is disposed towards aristocracy.

It is by means of bijection the individual is sustained within the communal. Although values are shared in communal identity, they are shared in differential sequencing. This sequencing is what distinguishes individuals. Community is sustained by injective mapping of sequenced whole to sequenced whole as an unbroken surjective transforming continuum.

\section{Conclusion}

Common behavior cannot occur without common content. Differently understanding what is, behavior is common only accidentally. Democracy being communal, and community being impossible if people do not identify the same objects, then democratic theory necessarily presumes they identify the same objects, whether potentially or actually.

Modern democratic theory presupposing solipsism, to preserve democracy, different sequencing of same objects must be assumed to account for difference. Proceeding thus, even if a constituent of solipsistic worlds is essentially common, whether potential or actual, necessarily it will be relationally uncommon. Individuals, therefore, will understand uncommon content. Communication is impossible. Communication being impossible, negotiation is impossible. Democracy being negotiated content, democracy is impossible.

Constituents of a solipsistic world not being relationally constituent of another solipsistic world, they compose a subjective world. Postulating a subjective world, and disclaiming an objective world, modern democratic theory accepts the reality of the individual, and the unreality of the communal. Democracy being communal, and democratic theories being individual, democratic theories are inconsistent with democracy. Being so, the challenge is to preserve democracy by identifying a means of bringing relativism into consistency with communalism.

Resolution is a logical, not practical, conception of democracy, theorists often confusing the two. Assuming relativism, impartiality is unattainable, it being impossible to judge independently of one's own world view. All that can be done is integrating the perceived world views of each into an uninterrupted whole within the individually solipsistic consciousness of each.

Required is inconstant sequencing of constant variables. Each sequence smoothly transitioning into another by reordering of the common variables integrates individual sequences into a single communal sequence. Many become one, and one becomes many in the cyclical transition from limit to limit of a commutative ring with unity.

Substantively, the interest of every one becomes the interest of every other. Each constituent member of an idealized democracy retains individual identity as a perspective on the integrated whole of all constituent interests. Rather than abandoned, one's interests are qualified by the interests of every other, which are taken on as one's own interests. Extended families perhaps most closely approach this state of affairs.

Distinguished is chaos from anarchy. Both assuming value relativism, chaos resolves disjunctives exclusively, whereas anarchy resolves disjunctives inclusively. Anarchy so represented integrates individual and communal identity. Not sacrificing either, lines are blurred, not drawn, composing a topological democracy of the commutative ring of logical equivalence.

\section{REFERENCES}

Baum, J. D. (1964). Elements of point set topology. New York: Dover. Bealer, G. (2008). Syllabus philosophy 634b, the philosophy of language: Frege's puzzle. New Haven, CT: Department of Philosophy, Yale University. http://www.yale.edu/philos/grad3.html

(1997). Behind the lines. Star trek: Deep space nine, episode 6x04, production number: 40510-528. http://www.youtube.com/watch?v=yfrOm3LuHBI

Bohm, D. (1989). Quantum theory. New York: Dover Publications.

Boyer, C. B. (1991). A history of mathematics (2nd ed.). U. C. Merzbach (Rvs.). New York: John Wiley \& Sons.

Colander, D. (2006). Microeconomics (6th ed.). Boston: McGraw-Hill Irwin.

Dewey, J. (1969-1975). Early Works (vol. 1). Carbondale, IL: Southern Illinois.

Fukuyama, F. (1989). The end of history? The National Interest, 3-18.

Gödel, K. (1963). Russell's mathematical logic. In P. A. Schilpp (Ed.), The philosophy of Bertrand Russell (pp. 123-153). New York: Harper \& Row.

Hobbes, T. (1651). De Cive. J.C. for R. Royston. London: Angel in Ivie-Lane. Source: Archive for the History of Economic Thought created by R. Hay. Hamilton, ON: McMaster University. http://www.marxists.org/reference/subject/philosophy/works/en/deci ve.htm

Hobbes, T. (1969). Leviathan. Cleveland: Meridian Books.

Kamke, E. (1950). Theory of sets. New York: Dover Publications.

Keay, D. (1987). Margaret Thatcher interview, "aids, education and the year 2000!" Woman's Own.

http://www.margaretthatcher.org/speeches/displaydocument.asp?doci $\mathrm{d}=106689$

Klir, G. J., \& Yuan, B. (2002). Fuzzy sets and fuzzy logic. New Delhi: Prentice-Hall of India.

Locke, J. (1952). The second treatise on government. Indianapolis: Bobbs-Merrill.

Marcus, R. B. (1971). Essential attribution. Journal of Philosophy, 68, 53-73.

McConnell, C. R. (1960). Elementary economics: Principles, problems, and policies. New York: McGraw-Hill Book Company.

Mish, F. C., et al. (1996). Merriam Webster's collegiate dictionary (10th ed.). Springfield, MA: Merriam-Webster.

Nozick, R. (1974). Anarchy, state, and utopia. New York: Basic Books.

Rand, A. (1964). The virtue of selfishness. New York: Penguin Books.

Rand, A. (1992). This is John Galt speaking. Atlas Shrugged. New York: New American Library.

Rawls, J. (1996). Political liberalism. New York: Columbia University.

Rouse, M. (2006). Quantum theory. WhatIs.com.

http://whatis.techtarget.com/definition/quantum-theory

Russell, B. (1960). Our knowledge of the external world. New York: A Mentor Book. 


\section{POOCHIGIAN}

Sandel, M. J. (2009). Justice: What's the right thing to do? New York: Farrar, Straus and Giroux.

Sen, A. (1995). Inequality reexamined. Cambridge, MA: Harvard. http://dx.doi.org/10.1093/0198289286.001.0001

Smith, A. (1984). The theory of moral sentiments. In: D. D. Raphael, \& A. L. Macfie (Eds.), Indianapolis: Liberty Fund.

Stewart, I. (1995). Concepts of modern mathematics. New York: Dover Publications.

http://searchcio-midmarket.techtarget.com/sDefinition/0,sid183_gci 332247,00.htm
Taylor, C. (2010). Solidarity in a pluralist age. R. Javaheri. “ABC democracy, political theory, democracy, and democratization. http://abcdemocracy.net/2010/09/28/charles-taylor-on-solidarity-in-a -pluralist-age/

Wittgenstein, L. (1968). Philosophical investigations. G. E. M. Anscombe (Trans.). New York: Macmillan.

Wittgenstein, L. (1974). Tractatus logico-philosophicus. D. F. Pears, \& B. F. McGuinness (Trans.). Atlantic Highlands, NJ: Humanities Press. 